\title{
Possible Evolution of Autoimmune Thyroiditis in Hypothyroidism: Role of Obesity
}

\author{
De Pergola $\mathrm{G}^{1 *}$, Ciampolillo $\mathrm{A}^{2}$, Tarantino $\mathrm{L}^{2}$, Trerotoli $\mathrm{P}^{3}$ \\ ${ }^{1}$ Department of Biomedical Sciences and Human Oncology, Section of Internal Medicine and Oncology, Italy \\ ${ }^{2}$ Department of Emergency and Organ Transplantation, Section of Internal Medicine, Endocrinology, Andrology and Metabolic Disease, Italy \\ ${ }^{3}$ Department of Biomedical Sciences and Human Oncology, Section of Statistics University of Bari "Aldo Moro", School of Medicine, Policlinico, Piazza \\ Giulio Cesare 11, 70124 Bari, Italy
}

Received: December 02, 2013; Accepted: May 05, 2014; Published: May 09, 2014

*Corresponding author: De Pergola G, Department of Biomedical Sciences and Human Oncology, Section of Internal Medicine and Oncology, Italy, Tel: 080 559.2742/080 559.4195; E-mail: gdepergola@libero.it

\begin{abstract}
Objective: It is not known whether the presence of obesity is responsible for a more severe autoimmune thyroiditis and consequently for a higher prevalence of hypothyroidism. The present study was addressed to investigate this aspect in a cohort of subjects, all affected by autoimmune thyroiditis, with a wide range of Body mass index (BMI) in euthyroidism or subclinical hypothyroidism.

Design: 311 subjects were enrolled : 160 of them underwent levothyroxine treatment, since they were affected by subclinical hypothyroidism, defined as having a TSH level higher than $4.0 \mu \mathrm{U} / \mathrm{ml}$ (Group 1); 151 subjects were affected by autoimmune thyroiditis, but they were euthyroid (TSH: 0.7- 3.0 $\mu \mathrm{U} / \mathrm{ml}$ ) (Group 2).

Methods: Family and medical history were carefully evaluated in all patients and, in particular, metabolic and cardiovascular diseases were investigated. Serum concentrations of FT4, FT3, TSH, antithyroglobulin (Tg-Ab) and antithyroperoxidase antibodies (TPOAb) were measured in all patients. BMI was calculated and thyroid morphology was evaluated using a high-resolution $7.5-\mathrm{MHz}$ linear transducer.

Results: Obesity (BMI $\geq 30.0$ ) was present in $44.4 \%$ of patients $(71 / 160)$ in Group 1, and only in $22.3 \%(29 / 151)$ of patients in group 2 ( $\mathbf{p}<\mathbf{0 . 0 0 0 1})$. A logistic model used to assess whether the need for levothyroxine therapy (dependent variable) is related to obesity (independent variables), suggested that this two parameters were significantly associated $(\mathrm{p}=0.03)$.

Conclusions: This study indicates that overweight and obesity increase the risk of autoimmune thyroiditis and subclinical hypothyroidism. It may be that higher production of adipokines characterizing obesity may involve the thyroid gland, thus favoring the development of autoimmune thyroiditis and subclinical hypothyroidism.
\end{abstract}

Keywords: Obesity; Autoimmune thyroiditis; BMI

\section{Introduction}

Autoimmune thyroid disease, and in particular Hashimoto's thyroiditis, (HT), is a common disease, affecting up to $2 \%$ of the population [1]. Its prevalence is related to age and gender, since it is 5- to 10-fold higher in women than in men [2,3], and to family history, since $40-50 \%$ of subjects affected by this disease have another member of the family with a thyroid disorder $[3,4]$. Different inheritance and environmental mechanisms are believed to be responsible of this disease. The most important environmental factors are cigarette smoking, psychological stress, iodine intake, intrauterine growth, bacterial and viral infections, and some drugs, such as interferon [3,5].

The natural course of autoimmunity and changes of thyroid function over time are unpredictable and commonly slow [611]. Studies in adults show that progression from euthyroidism or subclinical hypothyroidism (SCH) to clinical hypothyroidism is common. Higher thyrotropin levels at onset and a high titer of thyroid antibodies are predictive of an increased risk to develop hypothyroidism [1].

Obesity, especially central obesity, is linked to several endocrine abnormalities, including thyroid dysfunction .This is not surprising since T3 regulates energy metabolism and thermogenesis and plays a critical role in glucose and lipid metabolism [12]. TSH levels are at the upper limit of the normal range or slightly increased in obese children, adolescents, and adults, and are positively correlated with BMI [13-17]. Thyroid hormone levels have been reported to be normal, increased, and decreased in obese patients $[12,14,16-20]$; this discrepancy probably reflects differences in the level and in the type of obesity, insulin sensitivity and eating habits (overeating or hypo-caloric diet) among the studies.

Interestingly, a population study performed in 27,097 obese individuals (BMI $\geq 30.0 \mathrm{~kg} / \mathrm{m}^{2}$ ), with age $\geq 40 \mathrm{yr}$, has shown that subjects with subclinical or overt hypothyroidism had higher BMI [14]. Moreover, BMI and fat accumulation have been shown to be positively correlated with TSH concentrations [12,18-20] and negatively associated with serum FT4 levels [18-19] in overweight and obese subjects with subclinical hypothyroidism. 
Obesity (BMI $\geq 30 \mathrm{~kg} / \mathrm{m}^{2}$ ) has been shown to be a significant predictor of overt hypothyroidism in a cohort of older Australian [21]. Accordingly, subclinical hypothyroidism was associated with overweight and obese status in a cohort of children and adolescent [22]. In contrast with these studies, a moderate increase in total T3 or free T3 (FT3) levels has been reported in obese subjects $[13,16]$.

Concerning the possible interrelationship between obesity, thyroid function and autoimmune thyroiditis, a recent study showed a higher rate of subclinical hypothyroidism in patients with morbid obesity, but this alteration was not due to a higher rate of thyroid autoimmunity [23]. It is not known whether overweight and obesity may influence the natural course of the thyroid autoimmunity, indanthrene is some debate about the link between obesity and the risk of autoimmune thyroid dysfunction (AITD), which is the main cause of hypothyroidism in adults. The prevalence of AITD in obesity has been reported to be $12.4 \%$ in children and between 10 and $60 \%$ in adults [23,24].

It is not known whether the presence of obesity is responsible for a more severe autoimmune thyroiditis and, consequently, for a higher prevalence of hypothyroidism. The present study investigated this aspect in a cohort of subjects all affected by autoimmune thyroiditis, with a wide range of BMI, euthyroidism or subclinical hypothyroidism.

\section{Material and Methods}

We randomly recruited 311 patients affected by autoimmune thyroiditis in the Outpatient Clinic of the Section of Internal Medicine, Endocrinology, Andrology and Metabolic Disease of the Department of Emergency and Organ Transplantation of the University of Bari. The diagnosis of autoimmune thyroid disease was defined according to the Laboratory Medicine Practice Guidelines of the Guidelines Committee, National Academy of Clinical Biochemistry (25) by the presence of positive antibodies to thyroglobulin and/ or thyroid peroxidase.

Biochemical severity of thyroid dysfunction at diagnosis was determined from serum concentrations of free T4 and TSH.

In detail, 160 subjects (Group 1: 140 women and 20 men, mean age $57 . y \pm 12.7 y$ ) underwent levothyroxine treatment, since at the moment of the diagnosis they were affected by subclinical hypothyroidism, defined as having a TSH level higher than $4.0 \mu \mathrm{U} / \mathrm{ml}$, with a range from 4 to $10 \mu \mathrm{U} / \mathrm{ml}$. L-thyroxine treatment ranged between 50 and $100 \mu \mathrm{g} / \mathrm{die}$, in order to reach a condition of euthyroidism (TSH range between 1 and $2.5 \mu \mathrm{U} / \mathrm{ml}$ ). This condition were reached within 3 months.

151 subjects (Group 2: 130 females and 21 males, mean age: $48.3 \pm 15.9$ years) were affected by autoimmune thyroiditis, but in euthyroidism (TSH: $0.7-3.0 \mu \mathrm{U} / \mathrm{ml}$ ) at the moment of the diagnosis and they continued to be euthyroid without the treatment for at least 3 years.

Diagnosis of thyroid autoimmunity had been done in all 311 patients at least three years before. None of the patients was treated by a hypo-caloric diet at the moment of the enrollment. Each patient during the out patients visits were investigated about the compliance to the therapy and the assumed regularly the L-thyroxine

Serum concentrations of FT4, FT3, TSH, antithyroglobulin $\mathrm{Ab}(\mathrm{Tg}-\mathrm{Ab})$ and antithyroperoxidase $\mathrm{Ab}(\mathrm{TPOAb})$ were measured in all patients. BMI was calculated as the weight $(\mathrm{kg})$ divided by the square of height (mts). Serum concentrations of FT4 (normal range: 8.0-19.0 pg/ml), FT3 (normal range: $1.8-4.2 \mathrm{pg} /$ $\mathrm{ml}$ ), and TSH (third-generation TSH assay; normal range: 0.4$4.0 \mathrm{mIU} / \mathrm{l}$ ) were measured using immune-chemoluminescent assays by an automated analyzer (Immulite2000; Diagnostic Products Corporation Cirrus, Los Angeles, CA, USA), employing commercial kits (Diagnostic Products Corporation). Serum concentrations of $\mathrm{Tg}-\mathrm{Ab}$ (normal range: $<160 \mathrm{U} / \mathrm{ml}$ ) and TPO-Ab (normal range: $<160 \mathrm{U} / \mathrm{ml}$ ) were measured using immunochemoluminescent assays employing commercial kits (Brahms, Hennigsdorf, Germany). An accurate family and medical history was evaluated in all patients, investigating in particular metabolic and cardiovascular diseases. Ultrasound evaluation of the thyroid gland was carried out using a commercially available real-time instrument using a $7.5-10 \mathrm{MHz}$ linear transducer. The echo density of the thyroid was also examined and defined in comparison with the anatomic structures that are isoechoic (submandibular glands) or hypo echoic (neck muscles) with respect to the normal thyroid tissue. All examinations were be made by the same operator. Echogenicity was categorized as normal, decreased, or increased when compared with muscles.

\section{Statistical evaluation}

Quantitative variables were summarized as mean and standard deviation if Gaussian distributed. Median and interquartile range were used for variables without Gaussian distribution. Values of TSH are expressed as median and interquartile due to non-Gaussian distributed. Qualitative data were summarized as percentage and count.

A multiple logistic regression model was applied considering the treatment with levothyroxine as dependent variable and the obese/overweight phenotype as independent variable. Additional independent variables were age, sex, length of disease, and TSH levels. A stepwise selection was first performed, and sex and age were afterward entered in the final statistical model. All analyses were performed by SAS 9.1 software for PC, and statistical significance was assessed for p-values $<0.05$.

\section{Results}

We defined decreased echogenicity as the ecographic condition characterized by the score of +++ in comparison to the muscle echogenicity. All 311 patients showed a decreased echogenicity ranging between +++ and ++++ at ultrasounds, that is the ecographic pattern of the autoimmune thyroiditis.

Table 1 show the main characteristics of the study sample. Patients of the Group1 resulted positive for Tg-Ab in $96.88 \%$ $(155 / 160)$ while patients of the Group 2 resulted positive in $89.4 \%(135 / 151)$, the difference was statistically significant ( $\mathrm{p}=0.0087)$. All patients in both groups were positive for Anti TPO antibodies. 
The two groups were significantly different also regarding mean duration of the disease. All patients were diagnosed at least 3 years before the start of the study, but in group 1 mean duration of the disease was 6.16y (SD 3.6) while in group 2 mean duration of the disease was 4.1y (SD 2.8) ( $\mathrm{p}<0.0001)$.

The concentration of TSH was significantly different between the two samples, although in the normal range. Values are expressed as median and interquartile range: Group 1: 2.96 (first quartile-third quartile: 1.47-4.6) and Group 2: 2.2 (first quartilethird quartile: 1.5-3.2) ( $\mathrm{p}<0.001)$.

The analysis of associated pathologies has shown a statistically significant difference between the two groups: hypertension (p=0.0013) was present in $51.88 \%$ of the patients in Group 1 (83/160) vs. 33.7\% in Group 2 (51/151); type II diabetes $(\mathbf{p}<\mathbf{0 . 0 0 3 5})$ was present in $19.38 \%$ in Group1 (31/160) vs. $7.95 \%$ in Group 2 (12/151); hypercholesterolemia (p<0.0001) was present in $38.13 \%$ in Group $1(61 / 160)$ and in $14.57 \%$ in Group2 (22/151).

BMI categories between the two groups resulted statistically significantly different (Table 1). In Group1 there were a higher frequency of obese subjects $(44.4 \%, 71 / 160)$ in comparison to Group 2 (19.2\%, 29/151), while the frequency of normal weight people were higher in Group 2 (49\%, 74/151) with respect to Group1 $(25.6 \%, 41 / 160)$. In figure 1 the patients were classified in normal and obese people and compared: the percentage of obese patients was significantly higher in Group1 than in the Group 2 (p<0.0001).
The logistic model was used to assess if the need for levothyroxine therapy is related to the obese phenotype and other clinical variables such as age, sex, length of disease and TSH (Table 2).

Obese phenotype resulted a statistically significant risk factor (OR 2.56 CL95\% 1.09-6.03, p=0.0003). Other factors included in the model that significantly influence the need of levothyroxine therapy were TSH levels (OR 1.54, CL95\% 1.157-2.057, p=0.0031) as expected and duration of disease (OR 6.46, CL95\% 2.7-15.48, $\mathrm{p}<0.0001)$. Other factors, such as hypertension, diabetes mellitus type II, familiarity for thyroid pathologies; do not meet significant p-value to stay in the model.

\section{Discussion}

The present study, performed in a population of subjects all affected by decreased thyroid echogenicity and then by autoimmune thyroiditis, demonstrates that individuals affected by overweight or obesity are a higher prevalence of subclinical hypothyroidism.

Our logistic model confirmed that a more severe autoimmunity is associated with the presence of overweight or obesity that would accelerate the need of treatment with L-thyroxine. Concerning the mechanism explaining the link between obesity and the risk of autoimmune thyroid dysfunction (AITD), which is the main cause of hypothyroidism in adults, Marzullo et al found that leptin increases susceptibility to AITD by regulating immune processes [24]. Leptin levels were higher in AITD-positive obese patients than in AITD-negative patients, and the prevalence of

Table 1: Clinical characteristics of the 311 patients affected by the autoimmune thyroiditis

\begin{tabular}{|c|c|c|c|c|c|c|}
\hline & & \multirow{2}{*}{\multicolumn{2}{|c|}{$\begin{array}{c}\text { Group } 1 \\
\mathrm{~N}=160\end{array}$}} & \multirow{2}{*}{\multicolumn{2}{|c|}{$\begin{array}{c}\text { Group } 2 \\
\mathrm{~N}=151\end{array}$}} & \multirow[t]{3}{*}{ p-value } \\
\hline & & & & & & \\
\hline & & $\mathbf{n}$ & $\%$ & $\mathbf{n}$ & $\%$ & \\
\hline \multirow{2}{*}{ Sex } & M & 20 & 12.5 & 21 & 13.9 & $0.7139 *$ \\
\hline & $\mathrm{F}$ & 140 & 87.5 & 130 & 86.1 & \\
\hline \multirow{3}{*}{ BMI } & $<25$ & 41 & 25.6 & 74 & 49.0 & \\
\hline & $25-30$ & 48 & 30.0 & 48 & 31.8 & $<0.0001 *$ \\
\hline & $>30$ & 71 & 44.4 & 29 & 19.2 & \\
\hline \multirow{3}{*}{ Familiarity for thyroid pathology } & Mother & 129 & 80.6 & 119 & 78.81 & $0.6903^{*}$ \\
\hline & Father & 151 & 94.38 & 145 & 96.03 & $0.4969 *$ \\
\hline & Other & 104 & 65 & 96 & 63.58 & $0.7934^{*}$ \\
\hline \multirow{3}{*}{ Familiarity for } & Hypertension & 89 & 55.63 & 88 & 58.28 & $0.6368^{*}$ \\
\hline & Obesity & 147 & 91.88 & 143 & 94.7 & $0.3207^{*}$ \\
\hline & Type II diabetes & 94 & 58.75 & 90 & 59.6 & $0.8785^{*}$ \\
\hline \multicolumn{2}{|l|}{ AntiTg antibodies positive } & 155 & 96.88 & 135 & 89.4 & $0.0087 *$ \\
\hline \multicolumn{2}{|l|}{ AntiTPO antibodies positive } & 160 & & 151 & & \\
\hline \multirow{3}{*}{ Other pathologies } & Hypertension & 83 & 51.88 & 51 & 33.77 & $0.0013^{*}$ \\
\hline & Type II diabetes & 31 & 19.38 & 12 & 7.95 & $0.0035^{*}$ \\
\hline & Hypercholesterolemia & 61 & 38.13 & 22 & 14.57 & $<0.0001$ \\
\hline \multicolumn{2}{|l|}{ Age (mean. ds) } & 57.01 & 12.72 & 48.32 & 15.99 & $<0.0001^{\circ}$ \\
\hline \multicolumn{2}{|l|}{ Lenght of disease (mean. ds) } & 6.16 & 3.63 & 4.11 & 2.81 & $<0.0001^{\circ}$ \\
\hline \multicolumn{2}{|l|}{ TSH levels (median. first-third quartile) } & 2.96 & $1.47-4.6$ & 2.2 & $1.57-3.2$ & $<0.0001 \S$ \\
\hline
\end{tabular}




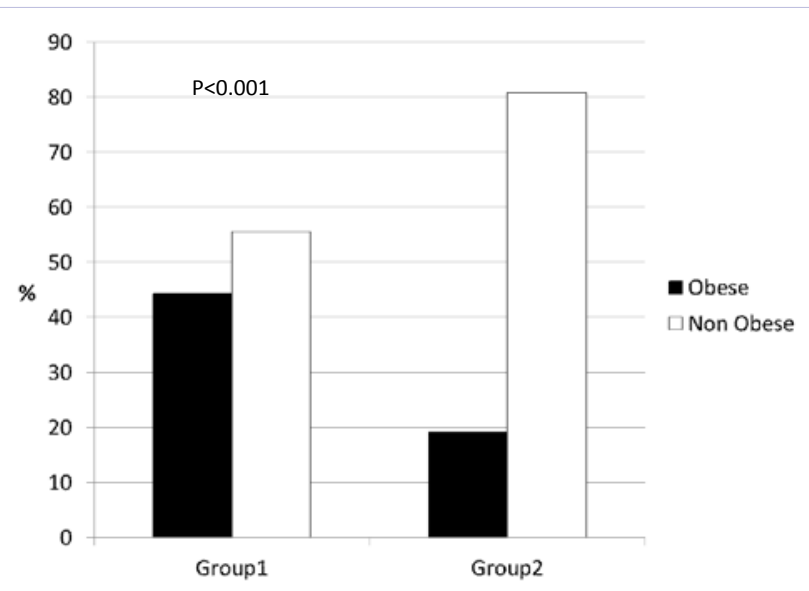

Figure 1: Comparison of obese and non obese people in the 2 groups of patients affected by the autoimmune thyroiditis.

Table 2: Logistic regression model to evaluate the treatment with levothyroxine as dependent variable, and the obese/overweight phenotype as independent variable. Additional independent variables were age, sex, length of disease, and TSH levels.

\begin{tabular}{|l|c|c|c|}
\hline Variables & Odds ratio & CI 95\% & p-value \\
\hline Obese vs Non Obese & 2.56 & $1.09-6.03$ & $\mathbf{0 . 0 3 0 7}$ \\
\hline Age & 1.01 & $0.99-1.04$ & 0.2469 \\
\hline Sex (M vs F) & 1.50 & $0.47-4.77$ & 0.4920 \\
\hline Lenght of disease & 6.46 & $2.70-15.48$ & $<\mathbf{0 . 0 0 0 1}$ \\
\hline TSH & 1.54 & $1.16-2.06$ & $\mathbf{0 . 0 0 3 1}$ \\
\hline
\end{tabular}

AITD was higher in patients with leptin levels above a median of $33.8 \mu \mathrm{g} /$ liter.

Apart from the possible role of leptin, chronic low-grade inflammation may well be a link between obesity, adipokine production, immune alterations, autoimmune thyroiditis and subclinical hypothyroidism. It is well known that obesity is a condition of low grade inflammation and that adipose tissue secretes a high quantity of other pro-inflammatory cytokines such as TNF- $\alpha$, IL-6, IL-1, etc, entering in the circulation, and inducing systemic inflammation that involves liver, skeletal muscle, and other tissues [26]. Inflammatory cytokines might also induce vasodilatation, thus increasing the vessel thyroid permeability, with plasma exudation, and possibly explaining thyroid ultrasound hypoechogenicity. Thyroid damage might also increase the risk of severe autoimmune thyroid disease. All these hypotheses are in line with a recent paper showing that Hashimoto's thyroiditis is associated to an increased intima-media thickness only in overweight and obese subjects, independently of the thyroid function, BMI and cardiovascular risk factors, suggesting that Hashimoto's thyroiditis is a marker of evolution of atherosclerosis whether combined to adiposity [27].

The difference in the prevalence of antithyroid antibodies between the two groups may be due to a different duration of the disease: the patients of group 2 , who did not need levo-thyroxine treatment, had a shorter length of the disease as compared to patients of group 1. Another difference between the two groups was the higher prevalence of co morbidities such as type II diabetes, hypertension, and hypercholesterolemia. It may well be that these findings are related to the higher prevalence of overweight and obesity in group 1 than in group 2, and it is well known that obesity is a risk factor for hypertension and type 2 diabetes [28].

In conclusion, the results of this study indicate that overweight and obesity increase the risk of autoimmune thyroiditis and subclinical hypothyroidism. It may well be that higher production of adipokines and generalized inflammation characterizing obesity may involve thyroid gland, generating autoimmune thyroiditis and subclinical hypothyroidism.

\section{References}

1. Tunbridge WM, Evered DC, Hall R, Appleton D, Brewis M, et al. (1977) The spectrum of thyroid disease in a community: the Whickham survey. Clin Endocrinol (Oxf) 7(6): 481-493.

2. Vanderpump MP, Tunbridge WM, French JM, Appleton D, Bates D, et al. (1995) The incidence of thyroid disorders in the community: a twenty-year follow-up of the Whickham Survey. Clin Endocrinol (Oxf) 43(1): 55 -68.

3. Manji N, Carr-Smith JD, Boelaert K, Allahabadia A, Armitage M, et al. (2006) Influences of age, gender, smoking, and family history on autoimmune thyroid disease phenotype. J Clin Endocrinol Metab 91(12): 4873-4880.

4. Tomer Y, Davies TF (2003) Searching for the autoimmune thyroid disease susceptibility genes: from gene mapping to gene function. Endocr Rev 24(5): 694-717.

5. Prummel MF, Strieder T, Wiersinga WM (2004) The environment and autoimmune thyroid diseases. Eur J Endocrinol 150(5): 605-618.

6. Dayan CM, Daniels GH (1996) Chronic autoimmune thyroiditis. N Engl J Med 335: 99-107.

7. Brown RS (1997) Thyroid disease in infancy, childhood and adolescence. In: Braverman LE (Ed.), Diseases of Thyroid. Humana Press, Totowa, New Jersy, USA.

8. Sklar CA, Qazi R, David R (1986) Juvenile autoimmune thyroiditis. Hormonal status at presentation and after long-term follow-up. Am J Dis Child 140(9): 877-880.

9. Rallison ML, Dobyns BM, Keating FR, Rall JE, Tyler FH (1975) Occurrence and natural history of chronic lymphocytic thyroiditis in childhood. J Pediatr 86(5): $675-682$.

10. Gruñeiro de Papendieck L, Iorcansky S, Rivarola MA, Bergadá C (1982) Variations in clinical, hormonal and serological expressions of chronic lymphocytic thyroiditis (CLT) in children and adolescents. Clin Endocrinol (Oxf) 16(1): 19-28.

11. Amino N, Tada H, Hidaka Y (2001) Chronic (Hashimoto's) thyroiditis. In: DeGroot LJ, Jameson JL, (eds) Endocrinology (4th ed) Philadelphia, PA: WB Saunders $1471-1480$.

12. Reinehr T, (2010) Obesity and thyroid function. Mol Cell Endocrinol 316(2): 165-171.

13. De Pergola G, Ciampolillo A, Paolotti S, Trerotoli P, Giorgino R, (2007) Free triiodothyronine and thyroid stimulating hormone are directly associated with waist circumference, independently of insulin resistance, 
metabolic parameters and blood pressure in overweight and obese women. Clin Endocrinol 67(2): 265-269.

14. Radetti G, Kleon W, Buzi F, Crivellaro C, Pappalardo L, et al. (2008) Thyroid function and structure are affected in childhood obesity. J Clin Endocrinol Metab 93(12): 4749-4754.

15. Iacobellis G, Ribaudo MC, Zappaterreno A, Iannucci CV, Leonetti F, et al. (2005) Relationship of thyroid function with body mass index, leptin, insulin sensitivity and adiponectin in euthyroid obese women. Clin Endocrinol(Oxf) 62(4): 487-491.

16. Nannipieri M, Cecchetti F, Anselmino M, Camastra S, Niccolini P, et al. (2009) Expression of thyrotropin and thyroid hormone receptors in adipose tissue of patients with morbid obesity and/or type 2 diabetes: effects of weight loss. Int J Obesity 2009 33(9): 1001-1006.

17. Kok P, Roelfsema F, Langendonk JG, Frölich M, Burggraaf J, et al. (2005) High circulating thyrotropin levels in obese women are reduced after body weight loss induced by caloric restriction. J Clin Endocrinol Metab 90(8): 4659-4663.

18. Alevizaki M, Saltiki K, Voidonikola P, Mantzou E, Papamichael C, et al. (2009) Free thyroxine is an independent predictor of subcutaneous fat in euthyroid individuals. Eur J Endocrinol 161(3): 459-65.

19. Knudsen N, Laurberg P, Rasmussen LB, Bülow I, Perrild H, et al. (2005) Small differences in thyroid function may be important for body mass index and the occurrence of obesity in the population. J Clin Endocrinol Metab 90(7): 4019-4024.

20. Fox CS, Pencina MJ, D'Agostino RB, Murabito JM, Seely EW, et al (2008) Relations of thyroid function to body weight: cross-sectional and longitudinal observations in a community- based sample. Arch Intern Med 168(6): 587-592.

21. Gopinath B, Wang JJ, Kifley A, Wall JR, Eastman CJ, et al. (2010) Five-year
Incidence and Progression of Thyroid Dysfunction in an Older Population. Intern Med J 170(17): 1605-1607.

22. Rapa A, Monzani A, Moia S, Vivenza D, Bellone S, et al. (2009) Subclinical hypothyroidism in children and adolescents: a wide range of clinical, biochemical, and genetic factors involved. J Clin Endocrinol Metab 94(7): 2414-2420.

23. Rotondi M, Leporati P, La Manna A, Pirali B, Mondello T, et al. (2009) Raised serum TSH levels in patients with morbid obesity: is it enough to diagnose subclinical hypothyroidism? Eur J Endocrinol. 160(3): 403-408.

24. Marzullo P, Minocci A, Tagliaferri MA, Guzzaloni G, Di Blasio A, et al. (2010) Investigations of thyroid hormones and antibodies in obesity: leptin levels are associated with thyroid autoimmunity independent of bioanthropometric, hormonal and weight-related determinants. J Clin Endocrinol Metab 95(8): 3965-3972.

25. Baloch Z, Carayon P, Conte-Devolx B, Demers LM, Feldt-Rasmussen U, et al. (2003) Laboratory Medicine Practice Guidelines. Laboratory support for the diagnosis and monitoring of thyroid disease. Thyroid 13(1): 3-126.

26. Mangge H, Almer G, Truschnig-Wilders M, Schmidt A, Gasser R, et al. (2010) Inflammation, adiponectin, obesity and cardiovascular risk. Curr Med Chem 17(36): 4511-4520.

27. Ciccone MM, De Pergola G, Porcelli MT, Scicchitano P, Caldarola P, et al. (2010) Increased carotid IMT in overweight and obese women affected by Hashimoto's thyroiditis: an adiposity and autoimmune linkage? BMC Cardiovascular Disorders 10:22.

28. Balkau B, Deanfield JE, Després JP, Bassand JP, Fox KA, et al. (2007) International Day for the Evaluation of Abdominal Obesity (IDEA): a study of waist circumference, cardiovascular disease, and diabetes mellitus in 168,000 primary care patients in 63 countries. Circulation 116(17): 1942-1951. 